\title{
Materi Pendidikan Akhlak menurut Al-Qur'an: Analisis Surah Al-Hujarat Ayat 11-12
}

\author{
Saiful Lutfi \\ Institut Agama Islam Negeri Palangka Raya, Indonesia, \\ saifullutfi1442@gmail.com
}

\begin{abstract}
ABSTRAK
Pendidikan Islam memainkan peranan penting dalam menciptakan manusia yang tidak hanya berkualitas pada intelektualitas saja, namun juga mulia pada tataran akhlak. Untuk mewujudkan peranan tersebut, maka pendidikan akhlak memiliki posisi yang sangat strategis dalam pendidikan Islam. Penelitian ini bertujuan untuk menganalisis materi pendidikan akhlak dalam surah Al-Hujarat ayat 11 dan 12. Penelitian ini merupakan jenis penelitian kualitatif dengan pendekatan studi kepustakaan. Data dianalisis menggunakan metode analisis isi. Berdasarkan analisis terhadap data penelitian, disimpulkan bahwa substansi nilai akhlak dalam surah Al-Hujarat ayat 11 dan 12 adalah tentang etika sosial seorang muslim dalam bermasyarakat. Substansi ajaran tentang etika sosial ini merupakan materi penting dalam pendidikan akhlak agar terwujud tatanan kehidupan sosial yang harmonis.

Kata Kunci: Pendidikan Islam, Akhlak, Al-Hujarat dan Al-Qur'an.
\end{abstract}

\begin{abstract}
Islamic education plays an important role in creating human beings who are not only of intellectual quality, but also noble at the moral level. To realize this role, moral education has a very strategic position in Islamic education. This study aims to analyze the moral education material in Surah Al-Hujarat verses 11 and 12. This research is a type of qualitative research with a literature study approach. Data were analyzed using content analysis methods. Based on the analysis of research data, it is concluded that the substance of moral values in the Al-Hujarat verses 11 and 12 is about the social ethics of a Muslim in society. The substance of the teachings on social ethics is an important material in moral education in order to create a harmonious social life order.Keywords: Islamic education, Morals, AlHujarat and Al-Qur'an.
\end{abstract}

Article History:

Received : 16-11-2020

Revised : 09-03-2021

Accepted : 12-04-2021

Copyright (c) Lutfi

\section{PENDAHULUAN}

Pendidikan Islam merupakan upaya membentuk pribadi yang berkontribusi pada masyarakat yang tidak hanya maju secara sains dan teknologi, tetapi juga memiliki 
moralitas. Dalam konteks Indonesia, pendidikan Islam berkontribusi dalam mewujudkan tujuan pendidikan nasional. Hal ini mengingat cakupan pendidikan Islam adalah keseimbangan antara sains teknologi dan akhlak. Perlunya keseimbangan ini mengingat Islam memandang bahwa kesuksesan tidak hanya mampu membangun peradaban yang unggul di dunia, namun juga mampu mendekatkan diri kepada Allah Swt (Muhammad, 2014).

Pendidikan Islam menekankan pentingnya penataan individual dan sosial pada setiap peserta didik. Penataan tersebut agar ajaran Islam dapat dilaksanakan secara komprehensif tidak hanya pada aspek ritual, namun juga pada aspek sosial. Pada tataran ini upaya untuk mewujudkan keseimbangan tersebut adalah melalui pendidikan akhlak kepada peserta didik sejak jenjang pendidikan dasar hingga perguruan tinggi. Hal ini karena dalam pendidikan Islam tujuan akhir dari proses pendidikan adalah terbentuknya akhlak yang mulia. Melalui pendidikan akhlak tersebut akan tercipta manusia yang tidak hanya memiliki kemampuan intelektual namun juga kemuliaan akhlak (Ghani, 2015; Munirah, 2017).

Sumber dari materi pendidikan Islam adalah Al-Qur'an. Pada tataran ini, isi Al-Qur'an mencakup seluruh dimensi kehidupan manusia tidak hanya berhubungan dengan ritual dan akidah, namun juga berhubungan dengan sains dan sosial kemasyarakatan. Keluasan cakupan isi Al-Qur'an menjadikannya senantiasa relevan sebagai sumber solusi atas permasalahan setiap zaman dan tempat. Untuk menggali substansi ajaran yang terkandung dalam Al-Qur'an tersebut dilakukan melalui kajian tafsir.

$$
\text { Al-Qur'an banyak }
$$
membicarakan tentang kemuliaan akhlak. Dalam konteks pendidikan Islam, diantara ayat yang secara spesifik membicarakan tentang akhlak terdapat pada surah AlHujarat ayat 11-12. Dalam konteks ini analisis terkait pendidikan akhlak dalam ayat tersebut dapat memberikan kontribusi pada pengembangan pendidikan akhlak.

Kajian terhadap surah AlHujarat ayat 11-12 dalam perspektif pendidikan Islam hingga saat ini cenderung diarahkan pada nilai-nilai akhlak. Beberapa kajian tersebut 
diantaranya dilakukan oleh Shudur (2016), Azamiyah (2017), Lestari (2017), Tang, Muslimah, dan Riadi (2020), serta Ramadan, Enoh, dan Junaedi (2017). Pada saat yang bersamaan, terdapat kekosongan kajian terkait desain dan kerangka materi pendidikan akhlak dalam surah Al-Hujarat ayat 11-12. Oleh karena itu, penelitian ini bertujuan untuk mengisi kekosongan kajian tersebut yaitu terkait dengan materi pendidikan Akhlak dalam surah AlHujarat ayat 11-12.

\section{METODE PENELITIAN}

Penelitian ini merupakan studi pustaka dengan pendekatan konten analisis kritis. Sumber data primer adalah teks Al-Qur'an surah AlHujarat ayat 11 dan 12. Sedangkan data sekunder adalah sumber tertulis baik berbentuk buku, jurnal, catatan maupun literatur lainnya yang dianggap relevan dengan penelitian ini. Data dikumpulkan melalui teknik dokumentasi. Data yang diperoleh kemudian akan dianalisis menggunakan teknik analisis isi.

\section{HASIL DAN PEMBAHASAN}

\section{A. Redaksi Ayat}

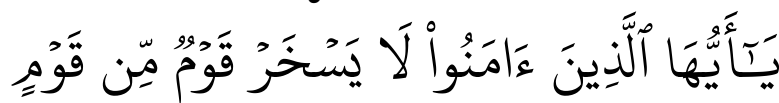

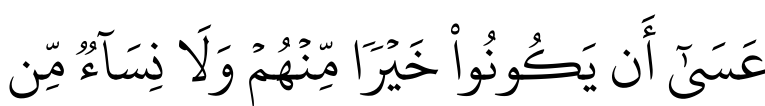

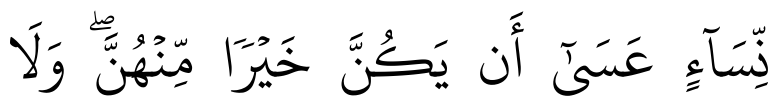

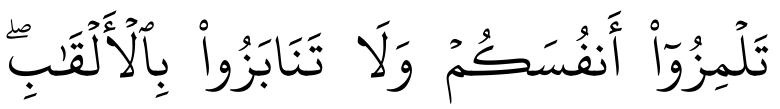

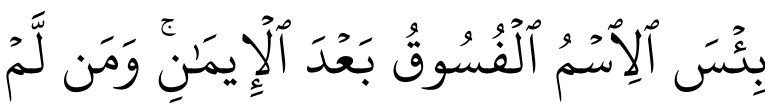

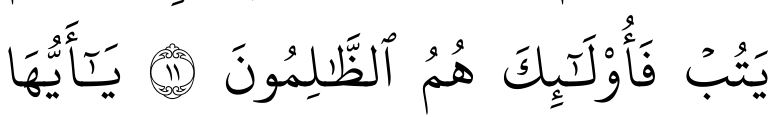

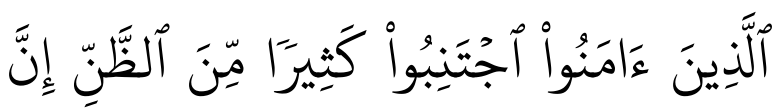

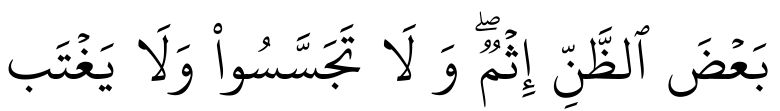

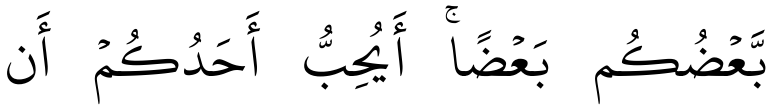

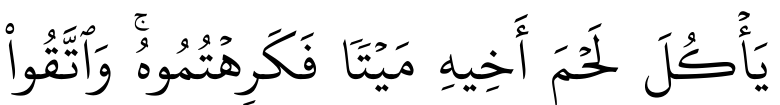

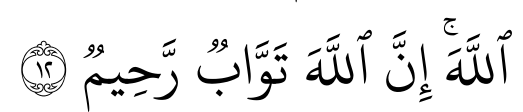
Terjemahan : Hai orang-orang yang beriman, janganlah sekumpulan orang laki-laki merendahkan kumpulan yang lain, boleh jadi yang ditertawakan itu lebih baik dari mereka. Dan jangan pula sekumpulan perempuan merendahkan kumpulan lainnya, boleh jadi yang direndahkan itu lebih baik. Dan janganlah suka mencela dirimu sendiri dan jangan memanggil dengan gelaran yang mengandung ejekan. Seburuk-buruk panggilan adalah (panggilan) yang buruk sesudah iman dan barangsiapa yang tidak bertobat, maka mereka itulah orang-orang yang zalim. Hai orang-orang yang beriman, jauhilah kebanyakan purba-sangka (kecurigaan), karena sebagian dari purba-sangka itu dosa. Dan janganlah mencari-cari keburukan orang dan janganlah menggunjingkan satu sama lain. Adakah seorang 
diantara kamu yang suka memakan daging saudaranya yang sudah mati? Maka tentulah kamu merasa jijik kepadanya. Dan bertakwalah kepada Allah. Sesungguhnya Allah Maha Penerima Taubat lagi Maha Penyayang

\section{B. Asbabun Nuzul ayat}

Asbabun nuzul dapat diartikan sebagai sebab yang melatarbelakangi turunnya ayat Al-Qur'an. Dalam kajian tafsir hingga abad 2 Hijriah asbabun nusul masih dipahami sebagai peristiwa atau sebab khusus atas turunnya ayat atau surah. Namun pada perkembangan selanjutnya, asbabun nuzul kemudian diklasifikasi menjadi dua yaitu mikro dan makro. Asbabun nuzul mikro adalah sebab khusus atau peristiwa yang melatarbelakangi turunnya suatu ayat atau surah Al-Qur'an. Sedangkan asbabun nuzul makro adalah kondisi sosio-historis masyarakat tempat suatu ayat atau surah Al-Qur'an diturunkan (Bakri, 2016; Wahyuddin, 2010).

Terdapat beberapa riwayat tentang Asbabun nuzul Al-Hujarat ayat 11. Pertama, riwayat yang mengatakan ayat tersebut terkait dengan ejekan yang diucapkan oleh seorang sahabat Nabi yaitu Tsabit ibn Qais. Dalam suatu majelis Tsabit melangkahi beberapa orang agar bisa duduk didekat Rasulullah. Sahabat lain menegur tingkah Tsabit tersebut, namun Tsabit marah kemudian memaki sahabat yang menegurnya. Ketika itu turunlah surah Al-Hujarat ayat 11 sebagai teguran atas tindakan Tsabit tersebut (Shihab, 2001). Kedua, riwayat yang mengatakan bahwa Rasulullah pernah memanggil seseorang lelaki dengan gelarnya. Namun seorang sahabat kemudian berkata untuk memberitahukan kepada Rasulullah bahwa gelar tersebut adalah gelar yang tidak disenangi orang yang dipanggil oleh Rasulullah (As-Suyuti, 2008). Terlepas dari perbedaan pendapat tentang riwayat asbabun nuzul dari ayat 11 surah Al-Hujarat, pada dasarnya kedua riwayat tersebut sama-sama menjelaskan tentang latar belakang turun ayat tersebut yaitu tentang peringatan agar tidak memaki dan mengejek serta memanggil orang lain dengan panggilan buruk atau tidak disenanginya.

Sedangkan asbabun nuzul AlHujarat ayat 12 disebutkan oleh AsSuyuti berdasarkan riwayat dari Ibn Mundzir adalah terkait dengan peristiwa seorang sahabat Nabi bernama Salman Al-Farisi setelah makan langsung tidur dengan 
mendengkur. Pada saat yang bersamaan seorang sahabat mengetahui peristiwa tersebut kemudian menceritakannya kepada orang lain. Kemudian ayat 12 dalam surah Al-Hujarat turun sebagai larangan bagi umat Islam untuk mengumpat, menggunjing, dan menyebarkan aib orang lain (AsSuyuti, 2008).

\section{Materi Pendidikan Akhlak}

\section{dalam Al-Hujarat ayat 11-12}

Akhlak merupakan orientasi utama dalam pendidikan Islam. Dalam konteks ini keberhasilan pendidikan dalam Islam tidak hanya diukur berdasarkan peningkatan kemampuan intelektual saja, namun juga ada perubahan lebih baik pada akhlak peserta didik (Rizal, 2015; Setiawan \& Pratama, 2018). Keseimbangan antara intelektual dan akhlak akan melahirkan sumber daya manusia unggul dan responsif terhadap berbagai isu kemanusiaan (Sabila, 2019; Saekan, 2017). Oleh karena itu wajar jika term akhlak seringkali menyertai ayat Al-Qur'an yang berhubungan dengan pendidikan.

Ayat 11 dan 12 dalam surah AlHujarat sangat berhubungan erat dengan materi yang ditemukan pada pendidikan akhlak terutama akhlak terhadap sesama. Secara spesifik materi pendidikan akhlak dalam ayat 11 dan 12 surah Al-Hujarat adalah tentang berbagai tindakan yang harus dihindari ketika berinteraksi dengan sesama manusia. Merujuk pada asbabun nuzul dan aspek kebahasaan dalam ayat tersebut setidaknya ada enam perbuatan yang harus dihindari dalam berinteraksi dengan sesama manusia.

Pertama, larangan menggejek sesama manusia. Term yang digunakan dalam Al-Qur'an untuk menunjukkan larangan mengolokolok atau mengejek adalah dengan kata يَسَخَرْ لَ (la yaskhar). Al-Maraghi (1993) menafsirkan yaskhar adalah sebagai perbuatan mentertawakan dan mengolok-olok, menceritakan aib dan kekurangan orang lain. Sejalan dengan itu, Shihab (2001) memandang bahwa yaskhar adalah istilah yang digunakan dalam ALQur'an untuk menunjukkan suatu tindakan membuka kekurangan orang lain agar ditertawakan dan direndahkan. Caranya bisa melalui ucapan, perbuatan, maupun bahasa nonverbal.

Kedua, larangan saling mencela. Term yang digunakan dalam 
Al-Hujarat ayat 11 untuk menunjukkan larangan mencela adalah تَلَمِزٌْ (talmizu). Menurut Asfahani (2008) larangan mencela yang ditunjukkan menggunakan redaksi talmizu termasuk juga dalam konteks membalas celaan yang orang lain. Shihab menjelaskan bahwa kata talmizu berakar dari kata al-lamz yang dapat diartikan dengan ejekan baik yang disampaikan secara verbal, isyarat bibir, maupun gestur. Tindakan tersebut menurut Ibn Asyur merupakan tidakan tidak beretika, bahkan masuk dalam kategori penganiayaan (Shihab, 2001). Ibn Katsir menafsirkan kata talmizu dengan larangan saling menghina, mencela, dan mengadu domba manusia lewat perkataan. Dalam pandangan Ibn Katsir, penggunaan term talmizu menunjukkan bahwa celaan dan hinaan akan memberikan dampak buruk tidak hanya pada orang yang dihina namun juga kepada yang melakukan hinaan (Ibn Katsir, 1986).

Ketiga, larangan memanggil dengan gelar yang buruk. Redaksi yang digunakan dalam Al-Hujarat ayat 11 terkait larangan tersebut adalah تَنَابزُْو (tanaabazu). Menurut Shihab (2001) akar dari kata tanaabazu adalah an-nabz yang artinya gelar buruk. Redaksi tanaabazu merupakan bentuk kata yang mengandung makna perbuatan timbal balik dan dilakukan secara terang-terangan. Dengan kata lain jika seseorang memanggil orang lain dengan panggilan buruk, kemudian dibalas juga dengan panggilan buruk maka dalam konteks itu sudah terjadi tanaabuz. Menurut Shihab kata alism yang disandingkan dengan kata tanaabazu tidak dapat diartikan dengan nama, tetapi lebih tepat pada sebutan, panggilan, dan gelar. Sebutan buruk tersebut baik yang berhubungan dengan kondisi fisik seperti si buta, maupun yang berhubungan dengan aib masa lalu seseorang seperti si pencuri (Shihab, 2001).

Keempat, larangan untuk berprasangka. Redaksi yang digunakan dalam surah Al-Hujarat ayat 12 terkait larangan tersebut adalah ألظَّنِّ (al-zann). Kata al-zann dapat diartikan sebagai prasangka, dugaan, perkiraan, tuduhan, dan kecurigaan yang belum pasti kebenarannya (Bisri \& Fatah, 1999). Menurut Shihab kata zann dalam AlHujarat ayat 12 konteksnya adalah senantiasa memberikan tuduhan dan 
prasangka buruk kepada orang lain (Shihab, 2001). Secara spesifik Hijazi memberikan kriteria terkait prasangka yang dilarang yaitu yang mengganggu dan membahayakan orang lain. Sedangkan prasangka sebagai bentuk kehati-hatian dan menjaga keselamatan tetap diperbolehkan (Hijazi, 1993).

Kelima, larangan mencari kesalahan orang lain. Redaksi yang digunakan dalam Al-Hujarat ayat 12 terkait larangan tersebut adalah تَجَسَُّ (tajassasu). Menurut Shihab (2001) akar kata tersebut adalah kata jassa yang dapat diartikan dengan matamata, atau upaya mencari tahu secara rahasia. Dalam pandangan Ath-Thabari ayat tersebut sebagai larangan mencari-cari keburukan seseorang atau kelompok, kemudian membuka rahasia tersebut kepada publik (Ath-Thabari, 2008). Sejalan dengan itu dalam pandangan Qutb, tajassus dapat diartikan dengan spionase, mencari-cari kesalahan orang lain sehingga sangat dilarang oleh Allah Swt (Qutb, 2003).

Keenam, larangan mengunjing. Redaksi yang digunakan dalam surah Al-Hujarat ayat 12 terkait larangan tersebut adalah يَنَّ (yaghtab). Menurut Shihab, akar kata tersebut
غيبة (ghibah) yang artinya menyebut keburukan orang lain tanpa diketahui orang tersebut (Shihab, 2001). Dalam pandangan AlMaraghi ghibah atau menggunjing tidak hanya dilakukan secara verbal (lisan) namun termasuk juga secara nonverbal sepanjang dipahami maksudnya (Al-Maraghi, 1993).

Keenam larangan yang berhubungan dengan materi pendidikan akhlak di atas pada dasarnya berhubungan dengan etika sosial. Materi etika sosial menjadi sangat penting dalam pendidikan akhlak terutama pada masyarakat multikultural. Hal ini mengingat dalam masyarakat multikultural etika sosial sangat menentukan terwujudnya tatanan masyarakat yang harmonis. Dalam konteks pendidikan Islam intelektualitas yang tinggi namun tidak ditopang dengan etika sosial yang baik akan sangat mungkin melahirkan manusia yang sombong, otoriter, dan tidak bermoral (Hamriah, 2012). Penggunaan kata $\gamma(l a)$ sebagai larangan pada setiap larangan tersebut menunjukkan adanya penekanan atas setiap larangan tersebut (Ahmadi \& Shobahiya, 2017). Penekanan tersebut bisa jadi karena akibat 
negatif jika tetap dilakukan seperti konflik sosial, kerusuhan, dan ketidakstabilan politik. Oleh karena itu dalam pandangan Maulani materimateri terkait etika sosial sangat penting dalam pendidikan agama (HM dkk., 2018; Maulani, 2012).

Implementasi etika sosial dalam Al-Hujarat ayat 11 dan 12 sebagai materi pendidikan akhlak sangat penting sebagai kontribusi pendidikan dalam mewujudkan harmonisasi sosial. Hal ini mengingat berbagai larangan yang ditemukan dalam Al-Hujarat ayat 11 dan 12 pada dasarnya adalah terkait erat dengan etika komunikasi dalam bermasyarakat. Realitas yang terjadi di Indonesia menunjukkan bahwa beberapa permasalahan yang terjadi di Indonesia seperti ujaran kebencian, konflik antar etnis seringkali disebabkan oleh ketiadaan etika dalam berkomunikasi (Andrian, 2020; Mutiah dkk., 2020; Yanuardanah \& Mualimin, 2020). Padahal beberapa pelakunya justru dari kalangan berpendidikan. Realitas tersebut menunjukkan bahwa komunikasi memainkan peranan penting dalam kehidupan manusia. Oleh karena itu, harmonisasi sosial dalam masyarakat dapat terbangun jika setiap orang mengedepankan etika dalam berkomunikasi (Khoiruddin, 2017).

\section{SIMPULAN}

Penelitian ini menemukan bahwa dalam surah Al-Hujarat ayat 11 dan 12 setidaknya ada enam nilai akhlak yang mesti diperhatikan dalam pendidikan Islam. Nilai tersebut yaitu larangan mengolokolok, larangan mencela dan membuka aib orang lain, larangan memanggil seseorang dengan panggilan buruk, larangan berprasangka buruk, larangan mencari-cari kesalahan orang lain, dan larangan mengunjing (ghibah). Keenam nilai akhlak yang ditemukan dalam surah Al-Hujarat ayat 11 dan 12 ini pada dasarnya berhubungan erat dengan etika seorang manusia dalam kehidupan sosial kemasyarakatan. Oleh karena itu berdasarkan analisis terhadap temuan tersebut disimpulkan bahwa nilai akhlak dalam surah Al-Hujarat ayat 11 dan 12 adalah tentang etika sosial seorang muslim dalam bermasyarakat. Substansi ajaran tentang etika sosial ini merupakan materi penting dalam pendidikan akhlak agar terwujud tatanan kehidupan sosial yang harmonis. 


\section{DAFTAR PUSTAKA}

Ahmadi, A. A. Z., \& Shobahiya, M. (2017). Penggunaan Kata "У" bermakna "Jangan" dalam Al-Qur'an (Perspektif Pendidikan Islam). Suhuf, 29(2), 125-138.

Al-Asfahani, A.-R. (2008). Mu'jam Mufradat Al-Faz Al-Qur'an. Dar Alkutub Al-Ilmiyah.

Al-Maraghi, A. M. (1993). Tafsir AlMaraghi, Terj. Anshori Umar Sitanggal. Karya Toha Putra.

Andrian, B. (2020). Komunikasi dan Akulturasi: Studi Fenomenologi pada Masyarakat Lokal dan Muslim di Perbatasan Indonesia-Malaysia. NALAR: Jurnal Peradaban dan Pemikiran Islam, 4(1), 51-63. https://doi.org/10.23971/njppi.v4i1. 1981

As-Suyuti, J. (2008). Lubabun Nuqul Fii Asbabin Nuzul Terj. Abdul Hayyie. Gema Insani Press.

Ath-Thabari, A. J. M. bin J. (2008). Jami' Al-Bayan At-Ta"wil Ayi AlQur'an Terj. Abdul Somad, Yusuf Hamdani (Vol. 13). Pustaka Azzam.

Azamiyah. (2017). Konsep Pendidikan Karakter Dalam Al-Qurean Surah AlHujarat: 11- 13. TADARUS, 6(1), Article 1. http://journal.umsurabaya.ac.id/index.php/Tadarus/a rticle/view/935

Bakri, S. (2016). Asbabun Nuzul: Diaog Antara Teks dan Realita Kesejarahan. Jurnal At-Tibyan: Jurnal Ilmu Alqur'an Dan Tafsir, 1(1), 1-18.

Bisri, A., \& Fatah, Munawir. A. (1999). Kamus Al-Bisri. Pustaka Progresif.

Ghani, A. (2015). Pendidikan Akhlak Mewujudkan Masyarakat Madani. AlTadzkiyyah: Jurnal Pendidikan Islam, 6(2), 273-284. https://doi.org/10.24042/atjpi.v6i2. 1518

Hamriah. (2012). Pendidikan Islam dan Pembinaan Etika Moral. Sulesana: Jurnal Wawasan Keislaman, $\quad 7(2), \quad$ 13-19. https://doi.org/10.24252/.v7i2.1371

Hijazi, M. (1993). Tafsir Al-Wadih. Dar Al-Jamil.

HM, A., Mualimin, \& Nurliana. (2018). Elit Agama dan Harmonisasi Sosial di Palangkaraya. Khazanah: Jurnal Studi Islam Dan Humaniora, 16(2), 277-296. https://doi.org/10.18592/khazanah. v16i2.2337

Ibn Katsir, A. al-F. I. (1986). Tafsir Ibnu Katsir. Al-Maktabah At-Tijariyah.

Khoiruddin, M. (2017). Etika Komunikasi dalam Al-Qur'an. DIDAKTIKA TAUHIDI: Jurnal Pendidikan Guru Sekolah Dasar, 2(1), Article https://doi.org/10.30997/dt.v2i1.30 3

Lestari, W. A. (2017). Konsep Pendidikan Akhlak dalam al-Qur'an Surat al-Hujurat Ayat 11 dan 12 (Kajian Perbandingan antara Tafsir alAzhar Buya Hamka dengan Tafsir alMishbah M. Quraish Shihab) [Skripsi, Universitas Islam Negeri Alauddin]. http:/ / repositori.uinalauddin.ac.id/5346/

Maulani, A. (2012). Tranformasi Learning dalam Pendidikan Multikultural Keberagaman. Jurnal Pembangunan Pendidikan: Fondasi Dan Aplikasi, 1(1), Article 1. https://doi.org/10.21831/jppfa.v1i1. 1049

Muhammad, A. (2014). Pendidikan Agama Islam dalam Membangun Etika Sosial (Telaah Pemikiran A. Qodri A. Azizy. Jurnal Penelitian 
Agama, 15(1), 1-25. https://doi.org/10.24090/jpa.v15i1. 2014.pp1-25

Munirah. (2017). Akhlak dalam Perspektif Pendidikan Islam. AULADUNA: Jurnal Pendidikan Dasar Islam, 4(2), 39-47.

Mutiah, T., Albar, I., Fitriyanto, F., \& Rafiq, A. (2020). Etika Komunikasi dalam menggunakan Media Sosial. Global Komunika: Jurnal Ilmu Sosial Dan Ilmu Politik, 1(1), 14-24.

Qutb, S. (2003). Tafsir Fi Zhilalil Qur'an: Di Bawah Naungan Al-Qur'an. Gema Insani Press.

Ramadan, S., Enoh, \& Junaedi, L. (2017). Implikasi Pendidikan dari Q.S Al-Hujurat Ayat 12 tentang Larangan Ghibah dan Upaya-upaya Menghindarinya. Prosiding Pendidikan Agama Islam, 3(1), 7-11. https://doi.org/10.29313/.v0i0.6080

Rizal, A. S. (2015). Orientasi Dan Konteks Sosial Pendidikan Islam: Memahami Dimensi Eksiologis Pendidikan Islam. taklim, 13(1). http://jurnal.upi.edu/taklim/view/3 334/orientasi-dan-konteks-sosialpendidikan-islam-:-memahamidimensi-eksiologis-pendidikanislam.html

Sabila, N. A. (2019). Integrasi Aqidah Dan Akhlak (Telaah Atas Pemikiran Al-Ghazali). NALAR: Jurnal Peradaban dan Pemikiran Islam, 3(2), 74-83. https://doi.org/10.23971/njppi.v3i2. 1211

Saekan, M. (2017). Ideologi Kemanusiaan dalam Pendidikan Islam. Edukasia: Jurnal Penelitian Pendidikan Islam, 12(1), 141-164. https://doi.org/ 10.21043/edukasia.v $12 \mathrm{i} 1.2263$

Setiawan, A. I., \& Pratama, M. A.-Q. (2018). Karakteristik Pendidikan Islam Periode Nabi Muhammad Di Makkah dan Madinah. NALAR: Jurnal Peradaban dan Pemikiran Islam, 2(2), 130-137.

https://doi.org/10.23971/njppi.v2i2. 958

Shihab, M. Q. (2001). Tafsir AlMisbah: Pesan, Kesan dan Keserasian Al-Qur'an (Vol. 13). Lentera Hati.

Shudur, M. M. (2016). Nilai-Nilai Pendidikan Akhlak dalam Al-Qur'an (Kajian Tafsir Surat Al-Hujurat Ayat 11-13). Sumbula: Jurnal Studi Keagamaan, Sosial Dan Budaya, 1(2). http:// ejournal.kopertais4.or.id/mat araman/index.php/sumbula/article/ view/2330

Tang S, M., Muslimah, \& Riadi, A. (2020). The Concept of Multicultural Education in Al-Qur'an Surah AlHujarat Verse 11-13. SYAMIL: Jurnal Pendidikan Agama Islam (Journal of Islamic Education), 8(2), 119-133. https://doi.org/10.21093/sy.v8i2.25 58

Wahyuddin, W. (2010). Asbabun Nuzul sebagai Langkah Awal Menafsirkan Al-Qur'an. Jurnal Sosial Humaniora, 3(2), 192-203. https://doi.org/10.12962/j24433527 .v3i2.649

Yanuardanah, \& Mualimin. (2020). Elit Agama dan Perdamaian: Pertemuan Imam Besar Al-Azhar dan Paus Fransiskus dalam Konstruksi Media. Hikmah, 14(2), 217-230. https://doi.org/10.24952/hik.v14i2. 2718 
Al-Mudarris : Jurnal Ilmiah Pendidikan Islam

p-ISSN: 2622-1993

Vol. 3, No. 2, November 2020, pp. 159-168

e-ISSN: 2622-1586 